J. Egypt. Soc. Parasitol. (JESP), 51(1), 2021: 107 - 112

(Online: 2090-2549)

\title{
CLINICO-SEROEPIDEMIOLOGICAL EVALUATION OF TOXOCARIASIS IN EGYPTIAN EPILEPTIC CHILDREN
}

\author{
By
}

WAEL A. ABOU-YAMAN ${ }^{1}$, GAMAL A. ABU-SHEISHAA ${ }^{1}$, AHMED M. $S$. BAYOUMY $^{* *}$ and KARIMA A. BAHGAT ${ }^{2}$

Department of Medical Parasitology, Faculty of Medicine ${ }^{1}$, and Department of Pediatrics, Neurology Unit, Faculty of Medicine (for Girls) ${ }^{2}$, Al-Azhar University ${ }^{1,2}$, Nasr City, Cairo, Egypt (Correspondence: drahmedbayoumy@azhar.edu.eg)

\section{Abstract}

Toxocariasis is one of the commonest zoonosis parasites worldwide, particularly in sheep-raising countries. Epilepsy is an important health problem in developing countries. The study assessed the seropositivity of toxocariasis in Egyptian idiopathic epileptic children. A case-control study was conducted on 125 children (1-18 years) with idiopathic epilepsy (patients) and 72 non-epileptic normal children (controls). All children underwent history taking, clinical examination, lab investigations, ELISA, and WB seropositivity to detect toxocariasis.

The results showed no significant difference in age, sex, and socioeconomic level, but a significant difference was in residence and pet dogs between patients and controls $(\mathrm{p}<0.05)$. Also, the Toxocara infection (ELISA) among patients was $41.6 \%$ versus $23.6 \%$ among controls and (Immunoblotting) $17.6 \%$ versus $5.5 \%$ respectively. There was an association between toxocariasis and epilepsy, with significant difference between patients and controls $(\mathrm{P}<0.05)$. Seropositivity was more in epileptic with generalized than partial seizures $(\mathrm{p}=0.06)$. As risk factors, residence and eating raw/undercooked meat showed significant difference and pet dogs and soil contact showed a highly significant difference in toxocariasis seropositive patients $(\mathrm{P}<0.05)$.

Keywords: Egyptian children, Toxocariasis, Idiopathic epilepsy,

\section{Introduction}

Toxocariasis, a disease caused by larvae of Toxocara canis, $T$. cati, and/or congeners infection, represented the clinical syndromes in man including visceral and ocular larva migrans, neurotoxocariasis, and covert/ common toxocariasis (Rostami et al, 2019). In North Africa, since 1990, the seroprevalence studies and case reports were done in six countries: Algeria, Egypt, Libya, Morocco, Sudan, and Tunisia (Adeel, 2020). The toxocariasis risk factors were contact with dogs and cats, which hairs being a potential risk factor for zoonotic transmission (Rojas et al, 2017). Also, contaminated soil with dog feces, foods and water, poor hygiene, lower education levels, and poverty provided ideal transmission opportunities (Congdon and Lloyd, 2011). Infection occurs by ingestion of embryonated eggs in contaminated soil, water, or food where the eggs or larvae exist (Ma et al, 2018), raw or undercooked meat, or organs from paratenic hosts (cows, sheep, or chicken) (Yoshikawa et al, 2008). Ingested eggs gave juvenile larvae that cross the small intestine and migrate to the somatic organs, preferably liver, brain, and eyes causing any of the four toxocariasis types: visceral, ocular, covert toxocariasis, and neurotoxocariasis with majority silent infections in human (Rubinsky-Elefant et al, 2010). The immunodiagnostic assays are enzymelinked immunosorbent assay (ELISA) and Western blotting (WB), both using Toxocara canis excretory-secretory (TES) antigens (Schantz and Glickman, 1978).

Epilepsy is one of the commonest neurological disorders among children especially in developing countries (Fisher et al, 2014). Two types were known; idiopathic epilepsy with unknown etiology and secondary epilepsy which originates from cerebral lesions that may be traumatic, hypoxic, or infectious in origin (Fisher et al, 2005). According to the Commission on Classification and Terminology of the International League Against Epilepsy (ILAE, 1993), cryptogenic (Idiopathic) epilepsy was defined as epilepsy syndromes with an unknown etiology, but the suspected underlying brain disease was up to 
60\% (Manford et al, 1992).

Childhood epilepsy is one of the most important neurological disorders in both developing and developed countries. Epilepsy has an impact on both the mental and physical health of children. Epileptic children may suffer from behavioral or psychiatric disorders, or social isolation due to social stigmatization (Camfield and Camfield, 2015). Several studies have been carried out suggesting a possible role of toxocariasis in the incidence of epilepsy (Quattrocchi et al, 2012).

The current study aimed to assess the toxocariasis seropositivity in Egyptian epileptic children.

\section{Subjects and Methods}

Study design: A case-control study was performed on 125 children (1-18years) with idiopathic epilepsy (epileptic group) and 72 healthy children (control group) during the period from June 2019 to April 2020. The purpose and procedures were explained and written informed consent was obtained from all parents of the included children.

The epileptic cases were chosen from the Outpatient Clinic of Pediatric Neurology Unit, Department of Pediatrics, Al-Zahraa University Hospital, Cairo, Egypt.

Diagnosis was based on the definition (ILAE, 1993) depending on number of head injuries, number of CNS infections (meningitis or encephalitis) or brain surgery, and normal magnetic resonance imaging (MRI) study and electroencephalogram (EEG). Control children were cross matched on age and sex attending the Outpatient Clinic for other causes with negative personal or family history of seizures.

All cases and controls were subjected to history taking through a questionnaire including personal data and toxocariasis risk factors as contact with animals (dogs and cats), soil contact or eating soil (geophagia), and eating raw or undercooked meat or drinking unsanitary water. Complete general and neurological examinations were done for all participants.

Ethical consideration: The study was app- roved by the Ethical Committee of Faculty of Medicine (Girls), Al-Azhar University.

Samples collection: Five milliliters of venous blood were taken from studied groups under complete aseptic conditions. Two $\mathrm{ml}$ of blood was collected in an EDTA tube to be used for the determination of differential leucocytic count for calculation of absolute eosinophilic count (Dacie and Lewis, 1992). The other $3 \mathrm{ml}$ was centrifuged at $2000 \mathrm{rpm}$ for 10 min., sera were kept at $-20^{\circ} \mathrm{C}$ in sterile labeled aliquots for serological analysis.

Serological investigation: Sera were tested for anti-Toxocara IgG antibodies detection using RIDASCREEN Toxocara-IgG ELISA (R-Biopharm AG, Darmstadt, Germany) kit which detects antibodies against the excretory/secretory antigen of Toxocara larvae. Serum samples were diluted and used for testing; each serum sample was tested in triplicates. Positive and negative controls were included in the kit according to the manufacturer's instructions. WB technique used a commercial kit (Toxocara WB IgG, LDBIO Diagnostic, Lyon, France). Strips were incubated with $1 / 100$ diluted sera for $2 \mathrm{hr}$ at room temperature than washed three times in PBS containing $0.1 \%$ Tween 20 , and then re-incubated for $2 \mathrm{hr}$ with second antibody, antihuman IgG peroxidase conjugate $(1: 1,000)$. Strips were washed again, diaminobenzidine was added and reaction was stopped by several washes in distilled water. Reaction was considered positive when it reacted with 2 or more of the supplied low-molecular-weight bands (LMWB; 24-35 kDa).

Statistical analysis: Data were coded, tabulated, and computerized for analysis using SPSS 18.0 (SPSS Inc., Chicago, IL.). Results were presented as frequencies and percentages. A chi-squared test compared data, and significant was at $\mathrm{P}$-value $<0.05$.

\section{Results}

The 125 idiopathic epilepsy children were $66(52.8 \%)$ males and $59(47.2 \%)$ females with ages ranged between 1-18 years (7.6 \pm 2.3$)$. The control was 72 healthy children, 39 (54.2\%) were males and 33(45.8\%) 
females with cross-matched ages, sex, and socioeconomic levels, but with a significant difference $(\mathrm{p}<0.05)$ in residence and $\operatorname{dog}$ ownership (Tab. 1).

Table 1: Sociodemographic data of groups

\begin{tabular}{|c|c|c|c|c|}
\hline \multicolumn{2}{|l|}{ Factors } & Epileptic children $(\mathrm{n}=125)$ & Control $(n=72)$ & P-value \\
\hline \multicolumn{2}{|c|}{ Age $($ Mean + SD) } & $7.6 \pm 2.3$ & $7.2 \pm 3.1$ & 0.3 \\
\hline \multirow{2}{*}{ Sex } & Male & $66(52.8)$ & $39(54.2)$ & 0.85 \\
\hline & Female & $59(47.2)$ & $33(45.8)$ & 0.88 \\
\hline \multirow{2}{*}{$\begin{array}{l}\text { Socioeconom- } \\
\text { ic level }\end{array}$} & Moderate & $58(46.4)$ & $43(59.7)$ & \multirow{2}{*}{0.72} \\
\hline & Low & $67(53.6)$ & $29(40.3)$ & \\
\hline \multirow{2}{*}{ Residence } & Urban & $45(44 \%)$ & $41(56.9)$ & \multirow{2}{*}{$0.003 * *$} \\
\hline & Rural & $80(56 \%)$ & $31(43.1)$ & \\
\hline \multicolumn{2}{|c|}{ Dogs/puppies ownership } & $78(62.4 \%)$ & $19(26.4 \%)$ & $0.0001 * *$ \\
\hline
\end{tabular}

Epileptic children (29.6\%) partial seizures 5 years and $(33.4 \%)$ above 5 years. Others and $(70.4 \%)$ generalized seizures, On age was $(4 \%)$ below 2 years, $(62.6 \%)$ between 2 $(12 \%)$ respiratory, $(5.6 \%)$ hepatic and gastrointestinal, and (1.6\%) ocular (Tab. 2).

Table 2: Clinical findings in epileptic group

\begin{tabular}{|l|l|l|}
\hline \multicolumn{2}{|c|}{ Epileptic children } & Frequency (\%) \\
\hline \multirow{2}{*}{ Epilepsy type } & Partial seizures & $37(29.6 \%)$ \\
\cline { 2 - 3 } & Generalized seizures & $88(70.4 \%)$ \\
\hline \multirow{3}{*}{ Epilepsy age of onset } & $<2$ years & $5(4 \%)$ \\
\cline { 2 - 3 } & $2-5$ years & $78(62.4 \%)$ \\
\cline { 2 - 3 } & $>5$ years & $42(33.6 \%)$ \\
\hline Respiratory symptoms (s\&sx) Fever, dyspnea, cough, chest pain, and wheezing & $15(12 \%)$ \\
\hline Hepatic \& GIT symptoms (s\&s s $_{\mathrm{x}}$ Abdominal pain, anorexia, nausea, vomiting, \& hepatomegaly & $7(5.6 \%)$ \\
\hline Ocular symptoms $\left(\mathrm{s} \& \mathrm{~s}_{\mathrm{x})}\right.$ Diminished vision/visual acuity, red-eye, and leukocoria & $2(1.6 \%)$ \\
\hline
\end{tabular}

Epileptic children showed 52 (41.6\%) Tox- ren compared to controls 4 (5.5\%), with sigocara ELISA-positive compared to controls $17(23.6 \%)$, with a significant difference $(\mathrm{P}=$ $0.011)$. Immunoblotting Toxocara-IgG positive were 22(17.6\%) among epileptic childTable 3: laboratory findings (eosinophilia and serology) in groups

\begin{tabular}{|l|l|l|l|l|}
\hline Laboratory Investigations & Epileptic children $(\mathrm{n}=125)$ & Control $(\mathrm{n}=72)$ & P-value \\
\hline \multirow{2}{*}{$\begin{array}{l}\text { Toxocara-IgG } \\
\text { ELISA }\end{array}$} & seropositive & $52(41.6 \%)$ & $17(23.6 \%)$ & \multirow{2}{*}{$0.011^{*}$} \\
\cline { 2 - 4 } & seronegative & $73(58.4 \%)$ & $55(76.4 \%)$ & \\
\hline $\begin{array}{l}\text { Toxocara-IgG } \\
\text { Immunoblotting }\end{array}$ & seropositive & $22(17.6 \%)$ & $4(5.5 \%)$ & \multirow{2}{*}{$0.016^{*}$} \\
\cline { 2 - 5 } & seronegative & $103(82.4 \%)$ & $68(94.4 \%)$ & \\
\hline High Eosinophilia & $60(48 \%)$ & $17(23.6 \%)$ & $0.0007^{* *}$ \\
\hline
\end{tabular}

Residence and eating raw/uncooked meat and soil showed a highly significant differshowed a significant difference. Dog contact ence as toxocariasis risk factor (Tab. 4). Table 4: Risk factors and epilepsy type in Toxocara seropositive epileptic group

\begin{tabular}{|c|c|c|c|c|}
\hline \multicolumn{2}{|l|}{ Risk Factors } & IgG positive $(n=22)$ & IgG negative $(\mathrm{n}=103)$ & P-value \\
\hline \multirow{2}{*}{ Age } & $<6 \mathrm{yrs}$ & $13(59.1 \%)$ & $58(56.3 \%)$ & \multirow{2}{*}{0.81} \\
\hline & $\geq 6 \mathrm{yrs}$ & $9(40.9 \%)$ & $45(43.7 \%)$ & \\
\hline \multirow{2}{*}{ Sex } & Male & $12(54.5 \%)$ & $53(51.5 \%)$ & \multirow{2}{*}{0.79} \\
\hline & Female & $10(45.5 \%)$ & $50(48.5 \%)$ & \\
\hline \multirow{2}{*}{$\begin{array}{l}\text { Socioeconomic } \\
\text { level }\end{array}$} & Moderate & $7(31.8 \%)$ & $53(51.4 \%)$ & \multirow{2}{*}{0.09} \\
\hline & Low & $15(68.1 \%)$ & $50(48.5 \%)$ & \\
\hline \multirow{2}{*}{ Residence } & Urban & $8(36.4 \%)$ & $24(55.3 \%)$ & \multirow{2}{*}{$0.01 *$} \\
\hline & Rural & $14(63.6 \%)$ & $56(44.7 \%)$ & \\
\hline \multicolumn{2}{|c|}{ Soil contact/geophagia (pica) } & $20(90.9 \%)$ & $24(23.3 \%)$ & $0.0001 * *$ \\
\hline \multicolumn{2}{|c|}{ Dog Contact } & $19(86.4 \%)$ & $56(54.4 \%)$ & $0.0001 * *$ \\
\hline \multicolumn{2}{|c|}{ Eating raw or undercooked meat } & $7(31.8 \%)$ & $12(11.7 \%)$ & $0.016^{*}$ \\
\hline \multirow{2}{*}{ Epilepsy type } & Partial seizures & $7(31.8 \%)$ & $30(29.1 \%)$ & \multirow{2}{*}{0.65} \\
\hline & Generalized seizures & $15(68.2 \%)$ & $73(70.9 \%)$ & \\
\hline
\end{tabular}

\section{Discussion}

Epilepsy is an important health problem, up to $80 \%$ of patients live in low or middle-

nificant difference $(\mathrm{P}=0.016)$. Epileptic children showed 60 (48\%) eosinophilia compared to controls $17(23.6 \%)$ with a highly significant $(\mathrm{P}<0.05)$ difference (Tab. 3). differ-

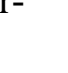


Newton, 2009).

In Egypt, the toxocariasis was encountered in man, edible animals and stray or pet-dogs (Khalil, 1977; Haridy et al, 2009; Morsy, 2020). Visceral toxocariasis occurred primarily in young children, especially between 27 years old (Stewart et al, 2005). Three most common organs or systems affected by Toxocara are the lungs, liver, and central nervous system. Presenting symptoms may be not specific as fever, fatigue, anorexia, and lymphadenopathy. Pulmonary symptoms were (cough, dyspnea, or wheezing) and abdominal symptoms (pain, hepatomegaly, or splenomegaly) when larvae migrate to lungs or abdominal organs, respectively, or CNS and eye causing ocular and neurotoxocariasis (Marx et al, 2007).

In the present study, there was no significant difference in age, sex, and socioeconomic level between epileptic children and controls. This agreed with Khademvatan et al. (2014), and Salama et al. (2019) who did not find difference as to age or sexes or economics among Toxocara positive epileptic patients, without differences in urban or rural areas. But, Eraky et al. (2016) reported more epileptic cases in rural areas.

In the present study, epileptic children showed $(29.6 \%)$ partial seizures compared to $(70.4 \%)$ generalized seizures, with $(4 \%)$ onset $<2$ years, $(62.6 \%)$ between 2-5years and $(33.4 \%)>5$ years, with respiratory $(12 \%)$, hepatic and gastrointestinal (5.6\%), and ocular $(1.6 \%)$ symptoms. This agreed with Salama et al. (2019) found that the seizures type was more among toxocariasis epileptic children compared to generalized ones but, without significant difference between them. Akyol et al. (2007) found non-significant difference between focal and generalized epilepsy, but, Nicoletti et al. (2008) found a significant association between toxocariasis and epilepsy, especially in partial epilepsy.

In the present study, ELISA-Toxocara positives were $41.6 \%$ in epileptic children versus 23.6 in controls and $17.6 \%$ versus $5.5 \%$ of control, and WB positively correlated bet- ween toxocariasis, and epilepsy $(\mathrm{P}<0.05)$. The agreed with Temsah et al. (2021) who found association between $T$. canis and bronchial asthma, chronic urticaria, and either unexplained cause of epilepsy or focal neurologic deficits.

Nicoletti et al. (2002; 2007; 2008) in Bolivia, Burundi, and Italy respectively, found significant association between anti- $T$. canis antibodies among epileptic patients and controls. Also, Kamuyu et al. (2014) in SubSahara of Africa correlated between pathogenesis of epilepsy/toxocariasis patients. Toxocara larvae stimulated granuloma formation around them that caused acute symptomatic seizures and then left after resolution of fibrous scars and chronic granulomatous lesions leading epilepsy (Wagner and Newton, 2009). The epilepsy autoimmune nature was due to antibodies to CNS major excitatory neurotransmitter (Levite and Ganor, 2008) stimulated by toxocariasis autoantibodies (Obwaller et al, 2004). Again, Winkler et al. (2008); Zibaei et al. (2013); Allahdin et al. (2015); El-Tantawy et al. (2013); Eraky et al. (2016) and Salama et al. (2019) neither found association between Toxocara positivity nor cryptogenic epileptic children or controls.

In the present study, high eosinophilia was in epileptic children (48\%) and in controls $(23.6 \%)$ with a high significant difference $(\mathrm{P}=0.0008)$. This agreed with Kwon et al. (2006), and Karadam et al. (2008) who reported that toxocariasis elevated eosinophilia in both peripheral blood and internal organs, with the marked elevation of IgM (Elsheikha et al, 2008).

In the present study, significant difference was among eating raw/undercooked meat, dogs, and soil contact as risk factors for toxocariasis/epilepsy $(\mathrm{P}<0.05)$. This agreed with Arpino et al. (1990) and Despommier et al. (2003) who reported that geophagia or soil eating pica increased toxocariasis risk. Also, Arpino et al. (1990); Fernando et al. (2007) and Salama et al, 2019) correlated between pet-dog and toxocariasis. But, Aky- 
ol et al. (2007) and El-Tantawy et al. (2013) did not find relationship between pica and toxocariasis in cryptogenic epileptic patients. Also, Fan et al. (2015) correlated between eating raw meat or liver and toxocariasis. But, Salama et al. (2019) did not find significant difference among positive or negative epileptic patients and raw meat.

\section{Conclusion}

Toxocariasis is worldwide zoonotic disease. The outcome data proved significant correlation between toxocariasis and epilepsy. Dogs and soil contact were major risk factors in rural areas. Health education and preventive measures were recommended.

\section{References}

Adeel, AA, 2020: Seroepidemiology of human toxocariasis in North Africa. Adv. Parasitol. 109:501-34.

Akyol, A, Bicerol, B, Ertug, S, Ertabaklar, H, Kiylioglu, N, 2007: Epilepsy and seropositivity rates of Toxocara canis and Toxoplasma gondii. Seizure 16, 3:233-7.

Allahdin, S, Khademvatan, S, Rafiei, A, Momen, A, Rafiei, R, 2015: Frequency of Toxoplasma and Toxocara sp. antibodies in epileptic patients, in South Western Iran. Iran. J. Child. Neurol. 9, 4:32-40.

Arpino, C, Gattinara, GC, Piergili D, Curatolo P, 1990: Toxocara infection and epilepsy in children: A case-control study. Epilepsia. 31, 1: 33-6.

Camfield, P, Camfield, C, 2015: Incidence, prevalence, and etiology of seizures and epilepsy in children. Epilept. Disord. 17:117-23.

Commission on Epidemiology and Prognosis, International League against Epilepsy, 1993: Epilepsia. Aug; 34(4):592 \pm 6 . PMID: 8330566

Congdon, P, Lloyd, P, 2011: Toxocara infection in the United States: The relevance of poverty, geography and demography as risk factors, and implications for estimating county prevalence. Int. J. Publ. Hlth. 56:15-24.

Dacie, JV, Lewis, SM, 1992: Basic hematological techniques. In: Practical Haematology. Churchill Livingstone, London.

Despommier, D, 2003: Toxocariasis: Clinical aspects, epidemiology, medical ecology, and molecular aspects. Clin. Microbiol. Rev. 16, 2: 265-72.

Elsheikha, HM, El-Beshbishi, SN, El-Shaz- ly, AM, Hafez, AO, Morsy, TA, 2008: Kinetics of eosinophilia and IgE production in experimental murine toxocariasis. J. Egypt. Soc. Parasitol. 38, 1:53-64.

El-Tantawy, NL, El-Nahas, HA, Salem, DA, Salem, NA, Hasaneen BM, 2013: Seroprevalence of Toxoplasma gondii and Toxocara spp. in children with cryptogenic epilepsy. Am. J. Infect. Dis. Microbiol. 1, 5:92-5.

Eraky, MA, Abdel-Hady, S, Abdallah KF, 2016: Seropositivity of Toxoplasma gondii and Toxocara spp. in children with cryptogenic epilepsy, Benha, Egypt. Korean J. Parasitol. 54, 3: 335-8.

Fan, CK, Holland CV, Loxton, K, Barghouth, U, 2015: Cerebral toxocariasis: Silent progression to neurodegenerative disorders? Clin. Microbiol. Rev. 28, 3:663-86.

Fernando, SD, Wickramasinghe, VP, Kapilananda, GM, Devasurendra, RL, Amarasooriya, JD, et al, 2007: Epidemiological aspects and risk factors of toxocariasis in a pediatric population in Sri-Lanka. Southeast Asian J. Trop. Med. Publ. Hlth. 38, 6:157-62.

Fisher, RS, Acevedo, C, Arzimanoglou, A, Bogacz A, Cross JH, et al, 2014: ILAE official report: A practical clinical definition of epilepsy. Epilepsia 55, 4:475-82

Fisher, RS, van Emde Boas, V, Blume, W, Elger, C, Genton P, et al, 2005: Epileptic seizures and epilepsy: Definitions proposed by the International League Against Epilepsy (ILAE) and the International Bureau for Epilepsy (IBE). Epilepsia. 46:470-2

Haridy, FM, Hassan, AAA, Hafez, AO, El-Sherbini, GT, Morsy, TA, 2009: External and intestinal parasites of pet dogs with reference to zoonotic toxocariasis. J. Egypt. Soc. Parasitol. 39, 1:321-6.

Kamuyu, G, Bottomley, C, Mageto, J, Lowe, B, Wilkins, PP, et al, 2014: Exposure to multiple parasites is associated with the prevalence of active convulsive epilepsy in sub-Saharan Africa. PLoS Negl. Trop. Dis. 8, 5:e2908.

Karadam, SY, Ertug, S, Ertabaklar, H, Okyay, P, 2008: The comparison of IgG antibodies specific to Toxocara spp. among eosinophilic \& non-eosinophilic groups. N. Microbiol. 31:113-6 Khademvatan, S, Khajeddin, N, Izad, S, Yousefi E, 2014: Investigation of anti-Toxocara and anti-Toxoplasma antibodies in patients with schizophrenia disorder. Schizophr. Res. Treat.http:// 
dx.doi.org/10.1155/2014/230349.

Khalil, HM, 1977: Toxocariasis in Egypt. J. Egypt. Publ. Hlth. Assoc. 52, 5:330-43.

Kwon, NH, Oh, MJ, Lee, SP, Choi, DC, 2006: The prevalence and diagnostic value of toxocariasis in unknown eosinophilia. Ann. Hematol. 85: 233-8.

Levite, M, Ganor, Y, 2008: Autoantibodies to glutamate receptors can damage the brain in epilepsy, systemic lupus erythematosus, and encephalitis. Expert Rev Neurother. 8, 7:1141-60.

Ma, G, Holland, CV, Wang, T, Hofmann, A, Fan CK, et al, 2018: Human toxocariasis. Lancet Infect. Dis. 18, 1: e14-24.

Manford, M, Hart, YM, Sander, JW, Shorvon, SD, 1992: The National General Practice Study of Epilepsy: The syndromic classification of the international league against epilepsy applied to epilepsy in a general population. Arch. Neurol. 49:801-8.

Marx, C, Lin, J, Masruha, MR, 2007: Toxocariasis of the CNS simulating acute disseminated encephalomyelitis, Neurology 69:806-7

Morsy, TA, 2020: Toxocariasis: Visceral and ocular larva migrans. J. Egypt. Soc. Parasitol. 50, No. 1:1-8

Nicoletti, A, Bartoloni, A, Reggio, A, Bartalesi, F, Roselli M, et al, 2002: Epilepsy, cysticercosis, and toxocariasis: A population-based casecontrol study in rural Bolivia. Neurology 58, 8: 1256-61.

Nicoletti, A, Bartoloni, A, Sofia, V, Mantilla, A, Nsengiyumva, G, et al, 2007: Epilepsy and toxocariasis: A case-control study in Burundi. Epilepsies 48, 5:894-9.

Nicoletti, A, Sofia, V, Mantella, A, Vitale, G, Contrafatto, D, et al, 2008: Epilepsy and toxocariasis: A case-control study in Italy. Epilepsies 49, 4:594-9.

Obwaller, A, Duchêne, M, Walochnik, J, Wiedermann, G, Auer, H, et al, 2004: Association of au-toantibodies against small nuclear ribonucleoproteins (snRNPs) with symptomatic Toxocara canis infection. Parasit. Immunol. 26, 8/9: 327-33.

Quattrocchi, G, Nicoletti, A, Marin, B, Bruno, E, Druet-Cabanac, et al, 2012: Toxocariasis and epilepsy: Systematic review and meta-analysis. PLoS. Negl. Trop. Dis. 6, 8:e1775.

Rojas, TO, Romero, C, Heredia, R, Bautista, LG, Sheinberg, G, 2017: Identification of Tox- ocara spp. eggs in dog hair and associated risk factors. Vet. Wld. 10, 7:798-802.

Rostami, A, Ma, G, Wang, T, Koehler, AV, Hofmann, A, et al, 2019: Human toxocariasis: A look at a neglected disease through an epidemiological prism. Infect. Genet. Evol. 74: 104002.

Rubinsky-Elefant, G, Hirata, CE, Yamamoto, JH, Ferreira MU, 2010: Human toxocariasis: Diagnosis, worldwide seroprevalences and clinical expression of the systemic and ocular forms. Ann. Trop. Med. Parasitol. 104, 1:3-23.

Salama, MA, Daod AA, Elshehawy, AK, Othman, AA, Eid MM, 2019: Toxocariasis and toxoplasmosis in children with idiopathic epilepsy in mid-region of the Nile Delta, Egypt: Prevalence and risk factors Inter. J. Curr. Microbiol. Appl. Sci. 8, 2:2319-7706

Schantz, PM, Glickman, LT, 1978: Toxocara, visceral larva migrans. N. Engl. J. Med. 298, 8: 436-9.

Stewart, J, Cubillan, LD, Cunningham, E, 2005: Prevalence, clinical features, and causes of vision loss among patients with ocular toxocariasis, Retina 25:1005-13

Temsah, K, Mostafa, M, El-khaleegy, H, El Rifai, A, Abd Raboo M, et al, 2021: Toxocariasis: A neglected tropical disease, association with asthma, chronic urticaria and unexplained neurologic manifestation among children. Inter. J. Med. Art. 3, 1:922-9.

Wagner, RG, Newton, CR, 2009: Do helminths cause epilepsy? Parasit. Immunol. 31, 11: 697-705.

WHO, 2019: Epilepsy: etiology, epidemiology and prognosis, Fact Sheet, No. 989.

Winkler, AS, Blocher, J, Auer, H, Gotwald, T, Matuja, W, et al, 2008: Anti-cysticercal and anti-toxocaral antibodies in people with epilepsy in Rural Tanzania. Trans. R. Soc. Trop. Med. Hyg. 102, 10:1032-8.

Yoshikawa, M, Nishiofuku, M, Moriya, K, Ouji, Y, Ishizaka, S, et al, 2008: A familial case of visceral toxocariasis due to consumption of raw bovine liver. Parasitol. Int. 57, 4:525-9.

Zibaei, M, Firoozeh, F, Bahrami, P, Sadjjadi, SM, 2013: Investigation of anti-Toxocara antibodies in epileptic patients and comparison of two methods: ELISA and Western blotting. Epilepsy Res Treat. 2013:156815. https://doi.org/ 10.1155/2013/156815 PMID: 23710354, 